\title{
A Siliciclastic Coastal Sabkha, Red Sea Coast, Saudi Arabia
}

\author{
A.K.A. Behairy, N.V.N. Durgaprasada Rao and A. EL-Shater \\ Faculty of Marine Science, King Abdulaziz University, \\ Jeddah, Saudi Arabia
}

\begin{abstract}
A modern, siliciclastic sabkha occupies the widespread, low lying and almost flat area to the east of Al-Kharrar lagoon on the west of Saudi Arabia. Four sedimentary facies were recognized in shallow cores: (1) surface sand layer associated with halite crust; (2) light brown clayeysandy unit displaying interstitial evaporatic minerals; (3) grey calcareous sandy unit which represents sediments accumulated during marine transgression; and (4) basal poorly sorted gravely-clayey sands of continental origin (Pre-Holocene alluvial deposits). The thickness of the sabkha and marine-lagoonal facies (facies $1,2,3$ ) in general decreases towards the south and east.

There are two evaporative assemblages in the studied sabkha. The first assemblage occurs in the southern part and includes gypsum, high $\mathrm{Mg}$-calcite and dolomite. It has formed through reworking of the sediments by flood water from the lagoon and subsequent rapid evaporation. The absence of aragonite in the surface sediments and its presence in those of the subsurface indicate that not only penecontemporaneous alteration of aragonite to dolomite but also later diagenetic processes have been active. The second assemblage in the central and northern parts of the sabkha is dominated by gypsura and high $\mathbf{M g}$-calcite in the surface sediments. Aragonite occurs only in subsurface sediments. $\mathrm{Mg}$ concentrations did not reach a level to initiate diagenetic dolomitization.

The observed mineralogical distribution is typical for coastal-marine evaporative system.
\end{abstract}

\section{Introduction}

Accumulation of extensive sedimentary evaporites has been attributed to primary and diagenetic processes involving sea-derived brines. So far there is full agreement 


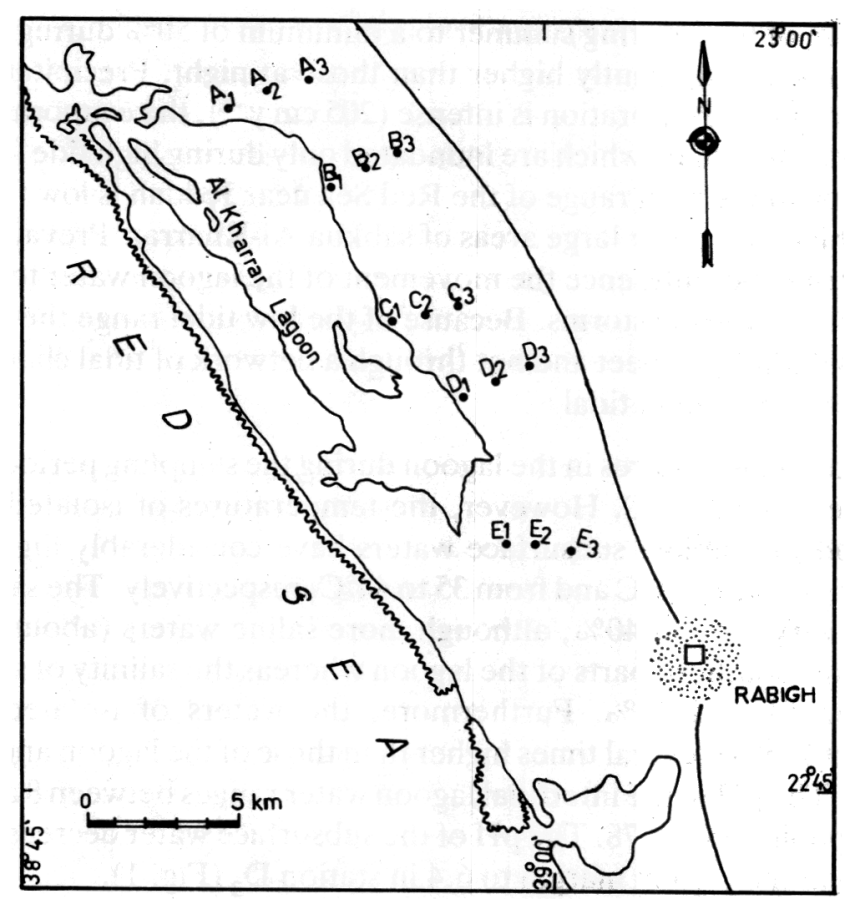

FIG. 1. Location of sediment cores and water samples in sabkha Al-Kharrar

The lagoon water enters the sabkhas by continuous subsurface seepage and sometimes by occasional floods. In some places, particularly in the northeastern part, an elevated sandy berm separates the sabkha from the lagoon. In this part, the low lying areas of the sabkha nearer to the lagoon are occasionally filled with water and subsequently evolve in the brine pools. The bottoms of these brine pools are covered with algal mats. Areas away from the lagoon are covered by a layer of permanently moist sediments. In the southern and southeastern sections where the sandy berm is absent, the lagoon water floods the sabkha which after evaporation, will be covered with a thin sheet of white salt crust. This salt crust will be dissolved in the next flooding but reappears after a few days creating a cycle process.

As the subsurface water mainly originates from the adjacent lagoon, the ground water level in the sabkha remains almost at the lagoon water level. Pits dug in different parts of the sabkha showed that the underground sea water extends more than 1 $\mathrm{km}$ landwards.

\section{Climate and Hydrography}

A hot arid climate is dominant in the west coast of Saudi Arabia. The air temperature during the sampling period varied from 31 to $35^{\circ} \mathrm{C}$ and the sabkha surface 
Representative sediment samples from cores were subjected to microscopical analyses and $\mathrm{x}$-ray diffraction. In addition, sand and mud content and total carbonate concentrations were estimated.

\section{Sedimentary facies}

The spatial arrangement of the facies is observed in the vertical profile of the cores taken from the sabkha. Four distinct lithological units can be recognized (Fig. 2).
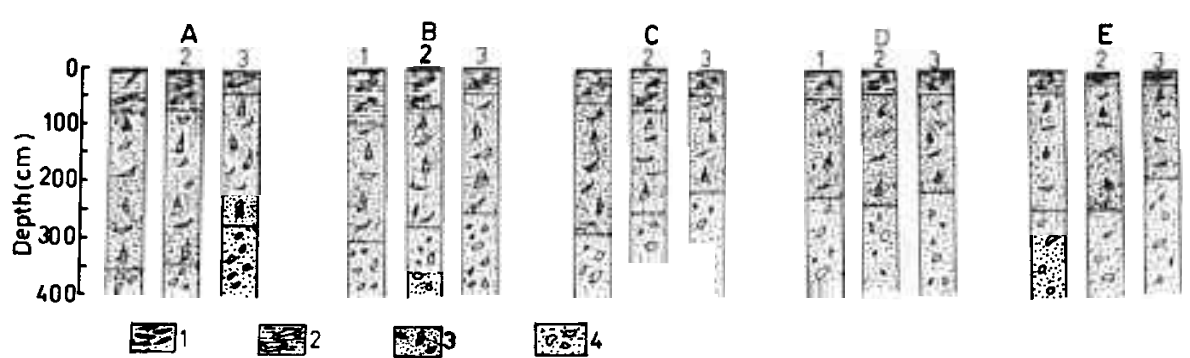

FIG. 2. Thickness and sedimentary facies of the cores in sabkha Al-Kharrar $(1=$ Unit I, $2=$ Unit II, $3=$ Unit III, 4 = Unit IV).

An uppermost unit of the surface quartz sand is usually up to $20 \mathrm{~cm}$ thick and commonly cemented by halite. Locally, the sand is mixed intimately and incorporated into algal mats.

The second unit ( $20 \mathrm{~cm}-1 \mathrm{~m}$ thick) is composed mainly of light brown medium to fine sands and clays. This unit is characterized by the presence of evaporitic minerals.

The third unit (1.5-3.7 $\mathrm{m}$ ) consists predominantly of grey coloured medium to fine sands with abundant amounts of shells and shell fragments. This unit contains less clay material than the former.

The basal unit shows a distinctive appearance of alluvial deposits of Pre-Holocene (Jado and Zotl 1984) and is composed mainly of reddish brown clastic sands with some gravels and clay of continental origin.

In general, it is clear from Fig. 2 that the thickness of both the second and third units decreases remarkably towards the south and the west.

\section{Mineralogy}

Microscopic examination and x-ray diffraction scans of the sediments showed that the bulk mineralogy of the sabkha Al-Kharrar sediments is composed mainly of quartz, feldspar, high $\mathrm{Mg}$-calcite, calcite, gypsum, halite, dolomite and aragonite (Fig. 4). The major evaporite and carbonate components in the upper first meter of these sediments are unevenly distributed with depth as seen in Fig. 3, where evaporitic minerals show a distinct distribution pattern. Gypsum is present only in the top 
The sediments in the areas that are directly influenced by the lagoon water during flooding are characterized by a dolomite assemblage whereas those in the areas influenced by lagoon water through seepage are characterized by an aragonite assemblage.

The minerological assemblage of the suspended sediments in the evaporitic brine pools in the sabkha is dominated by halite, dolomite, high $\mathrm{Mg}$-calcite and some gypsum (Fig. 5).

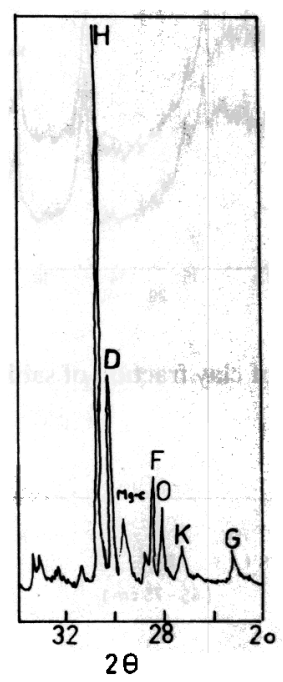

FIG. 5. $X$-ray diffraction pattern of a brine pool suspended sediment from sabkha Al-Kharrar (G-gypsum, $\mathrm{Q}$ - quartz, $\mathrm{F}$ - feldspar, $\mathrm{Mg}-\mathrm{C}$ - high $\mathrm{Mg}$ calcite, $\mathrm{D}$ - dolomite, $\mathrm{H}$ - halite).

Apart from the minerals described above, clay minerals are recorded in the fine fractions of the sabkha sediments. The main species of these minerals in decreasing abundance are illite, kaolinite and chlorite. Palygorskite was recorded in minor amounts in some sediments (Fig. 6).

\section{Geochemistry}

The distribution pattern of chlorinity, density and $\mathrm{Mg} / \mathrm{Ca}, \mathrm{Ca} / \mathrm{Cl}, \mathrm{SO}_{4}^{-2} / \mathrm{Cl}$ molar ratios in the sabkha surface water, evaporite pools water and Al-Kharrar lagoon water are presented in Fig. 7.

\section{Chlorinity}

From the lagoon margin across the sabkha, the brine chlorinity generally rises to a maximum and decreases again towards the inland margin (Fig. 7 . Similar results have been observed in other sabkhas (e.g. Butler 1969, Gavish 1980). 

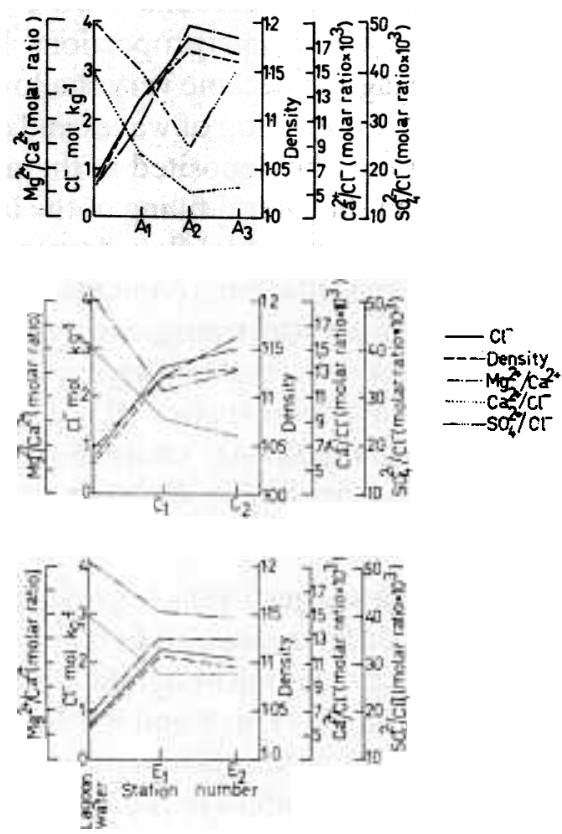

FIG. 7. Variations in chlorinity, density, $\mathrm{Mg} / \mathrm{Ca}, \mathrm{Ca} / \mathrm{Cl}$ and $\mathrm{SO}_{4}^{-2} / \mathrm{Cl}^{-}$molar ratios in the subsurface waters at different stations in sabkha $\mathrm{Al}$-Kharrar.

\section{Sulphate and calcium ratios}

$\mathrm{SO}_{4}^{-2} \mathrm{Cl}$ and $\mathrm{Ca} / \mathrm{Cl}$ ratios in the subsurface waters generally decrease towards the inland margin. Such a decrease is due to the precipitation of calcium carbonate and gypsum in the sabkha sediments.

\section{Magnesium/Calcium ratios}

$\mathrm{Mg} / \mathrm{Ca}$ ratios in the subsurface waters are relatively higher than those of sea water and lagoon water. The high $\mathrm{Mg} / \mathrm{Ca}$ ratios are attained by the precipitation of calcium ions as carbonate and sulfate. Brines with high $\mathrm{Mg} / \mathrm{Ca}$ ratio could form dolomite. Bush (1973) stated that when the $\mathrm{Mg} / \mathrm{Ca}$ ratio reaches approximately $10: 1$, dolomitization of fine-grained aragonite occurs to produce fine-grained dolomites.

\section{Discussion}

The sedimentary sequences in the sabkha of Al-Kharrar indicate that water level variations in the lagoon associated with sea level fluctuations in the Red Sea and variations in the supply of clastic material from the adjacent mountains produced a variety of sedimentary facies. During the Holocene transgression, alluvial deposits (the basal unit) were flooded by Sharm Al-Kharrar waters and a shallow lagoonal environment was developed (Behairy 1983). In this environment, the third facies with 
The two evaporite mineral assemblages recorded in the sabkha Al-Kharrar appear to be related to the degree of restriction in the availability of lagoon water. In the southern and south-eastern parts, the lagoon waters flooding the sabkha are rapidly evaporated to a degree that permits high $\mathrm{Mg}$-calcite and dolomite to have been precipitated in addition to gypsum. These conditions are comparable to the isolated brine pools where a closed evaporite system result in concentrated brines rich in $\mathrm{Mg}$ and leads to precipitation of Mg-calcite, gypsum and dolomite. Absence of aragonite in these two places suggests that either the high $\mathrm{Mg}$ concentrations prevented aragonite formation or to the penecontemporaneous transformation of aragonite to dolomite. Guantilaka et al. (1984) reported penecontemporaneous replacement of aragonite by dolomite in a subtidal environment of a hypersaline lagoon in Kuwait. However, the occurrence of aragonite in some of subsurface sediments indicates not only penecontemporaneous replacement but also later diagenetic processes. Levy (1977) noticed that dolomite occurring in some of the sabkhas was formed diagenetically through the interaction between formerly precipitated calcium carbonates and concentrated marine brines rich in magnesium.

In the central and northern parts of the sabkha both aragonite and dolomite are absent in the surface sediments where gypsum and high Mg-calcite dominate. However, aragonite occurs in the subsurface sediments. Dolomite is noticed only in one subsurface sample away from the lagoon. Such a distribution pattern of the minerals indicates evaporation from sea water. Gavish (1980) noted that increase in the concentration of brines as they move upwards causes firstly the precipitation of carbonates, then above of them sulphate and finally halite (Fig. 3). The lagoon water enters the sabkha through subsurface seepage and becomes concentrated by evaporation through the sediment cover. The mechanism of evaporative pumping (Hsu and Siegenthaler 1969; Hsu and Schneider 1973) is responsible for the upward migration of the concentrated lagoon water. Furthermore, the increasing salinities of the subsurface waters landward maintain the flow of water from the lagoon to the sabkha. Lack of direct supply of lagoon water and evaporation at the surface such as in the southern part of the sabkha might have prevented the development of concentrated brines rich in $\mathrm{Mg}$ for the formation of dolomite. Persistence of aragonite in the subsurface sediments also indicates that $\mathrm{Mg}$ concentrations did not reach a level to initiate diagenetic dolomitization of aragonite. This hypothesis is supported by hydrochemical data (Fig. 7) which show lower $\mathrm{Mg} / \mathrm{Ca}$ molar ratio of the subsurface waters in these parts of sabkha compared to the southern region and to the evaporitic pools.

\section{References}

Alderman, A.R. (1965) Dolomitic sediments in their environment in the southeast of South Australia, Geochim, Cosmochim. Acta 29: 1355-1365.

Behairy, A.K.A., Meshal, A.H. and Osman, M.M. (1980) Evaporation from the coastal zone of the Red Sea, J. Mar. Res. 1: 3-10.

Behairy, A.K.A. (1983) Marine transgressions in the west coast of Saudi Arabia between Mid-Pleistocene and nresent. Mar. Geol. 52: 25-32. 


\title{
سبخـة شاطئيـة سليسيـة على شاطيء البحر الأحمر بالمملكة العربيـة السعوديـة
}

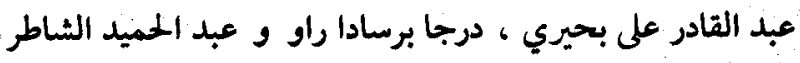

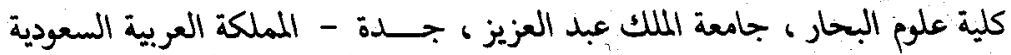

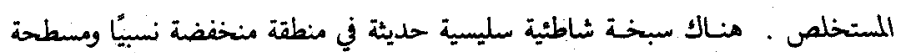

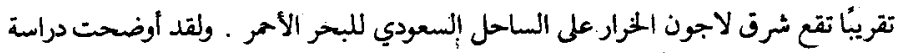

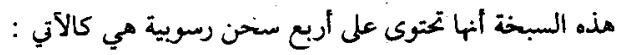

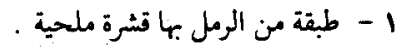
Y

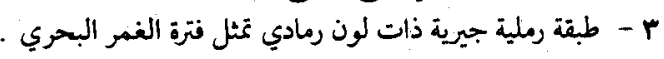

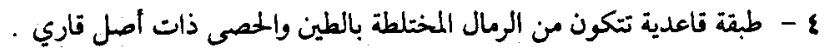

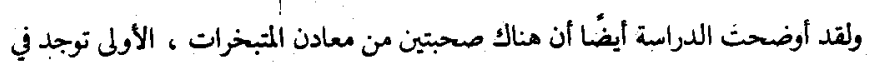

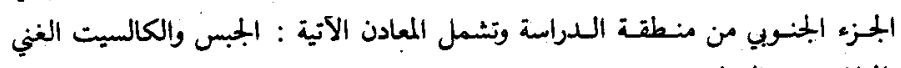

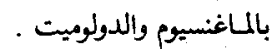

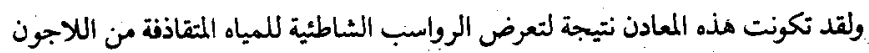

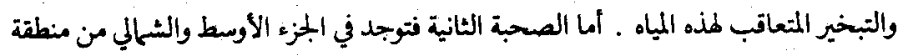

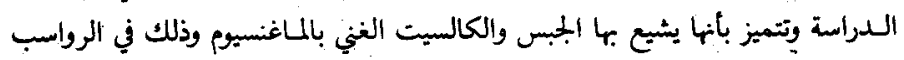

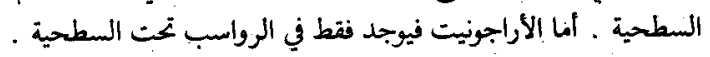

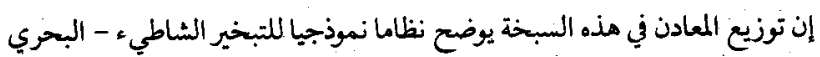

